FEDERAL

RESERVE

BANK of

ST. LOUIS
RESEARCH DIVISION

Working Paper Series

\title{
Why do Education Vouchers Fail at the Ballot Box?
}

\author{
Peter Bearse, \\ Buly A. Cardak, \\ Gerhard Glomm \\ and \\ B. Ravikumar
}

\author{
Working Paper 2011-032B \\ https://doi.org/10.20955/wp.2011.032
}

May 2013

\author{
FEDERAL RESERVE BANK OF ST. LOUIS \\ Research Division \\ P.O. Box 442 \\ St. Louis, MO 63166
}

The views expressed are those of the individual authors and do not necessarily reflect official positions of the Federal Reserve Bank of St. Louis, the Federal Reserve System, or the Board of Governors.

Federal Reserve Bank of St. Louis Working Papers are preliminary materials circulated to stimulate discussion and critical comment. References in publications to Federal Reserve Bank of St. Louis Working Papers (other than an acknowledgment that the writer has had access to unpublished material) should be cleared with the author or authors. 


\title{
Why Do Education Vouchers Fail at the Ballot Box?*
}

\author{
Peter Bearse ${ }^{\dagger}$ Buly A. Cardak Gerhard Glomm $^{\S} \quad$ B. Ravikumar
}

\author{
August 2009 \\ Revised December 2011 \\ This version August 2012
}

\begin{abstract}
We compare a uniform voucher regime against the status quo mix of public and private education, focusing on the distribution of welfare gains and losses across households by income. We argue that the topping-up option available under uniform vouchers is not sufficiently valuable for the poorer households, so the voucher regime is defeated at the polls. Our result is robust to partial voter turnout and efficiency differences between public and private schools, but depends critically on the opting-out feature in the current system.
\end{abstract}

${ }^{*}$ We are thankful to two anonymous referees for their helpful comments. We would also like to thank Marco Basetto, V.V. Chari, Gianni De Fraja, Ray Riezman, Rich Romano, Jon Sonstelie, Itzhak Zilcha, seminar participants at Ben Gurion University, Tel Aviv University, the Federal Reserve Bank of Chicago, the Federal Reserve Bank of Minneapolis, the University of Illinois, and The Melbourne Institute, and conference participants at the Meeting of the Society for Economic Dynamics in San Jose, Costa Rica, the Winter Meetings of the Econometric Society in Atlanta, GA, the CEPR/IHS Conference on Dynamic Aspects of Policy Reform in Vienna, Austria, the Public Economic Theory meetings in Galway, Ireland, and the Australasian Public Choice Conference in Melbourne, Australia. We also thank Judith Ahlers and George Fortier for their editorial assistance. The views expressed in this article are those of the authors and do not necessarily reflect the views of the Federal Reserve Bank of St. Louis or the Federal Reserve System. Any remaining shortcomings are entirely our own.

${ }^{\dagger}$ Department of Economics, 462 Bryan School of Business and Economics, University of North Carolina at Greensboro, Greensboro, NC 27402-6165, bearse@uncg.edu

${ }^{\ddagger}$ School of Economics and Finance, La Trobe University, Victoria 3086, Australia, b.cardak@latrobe.edu.au

${ }^{\S}$ Corresponding author: Department of Economics, Wylie Hall, Room 105, Indiana University, Bloomington, IN 47405, gglomm@indiana.edu

IResearch Division, Federal Reserve Bank of St. Louis, P.O. Box 442, St. Louis, MO 63166, b.ravikumar@wustl.edu 


\section{Introduction}

School vouchers are a hotly debated topic in the U.S. State voucher proposals often involve large and vocal campaigns by opponents and supporters. There are a few voucher systems in place in the U.S., but large-scale voucher systems are rare. The lack of voucher systems is not limited to the U.S. The coexistence of public and private education seems to be the predominant institutional arrangement worldwide (see James, 1987).

In this paper we examine the political support for or opposition to education vouchers that are put to a public vote. Specifically, we quantify the welfare gains and losses to households in different income classes when we switch from the status quo to a uniform voucher regime. To illustrate our findings, we use the model of Epple and Romano (1996a) and Glomm and Ravikumar (1998) as our status quo education finance regime. In that model, both public and private schools coexist. All households pay income taxes to fund public education, but they can opt out of public education to attend a private school of their choice at their own cost. The funding level for public education in this mixed publicprivate regime is determined through majority voting by the median voter. We compare the status quo against a uniform voucher economy similar to the one recommended by Friedman (1962). In our voucher economy, the government collects taxes on income and uses the tax revenue to finance education vouchers. Each school-age child receives the same voucher amount. Unlike the status quo mix of public and private education, the government does not provide education in our voucher economy; it only finances education. Given the voucher amount each child receives, households determine the level of educational services for their children. Some households use their after-tax income to supplement vouchers (and reduce their expenditures on other goods), while others do not.

In our model, the uniform voucher regime provides households the option of "topping up," whereas the status quo does not. For a household whose allocation in the status quo is such that the marginal rate of substitution (MRS) of education for other goods is greater than the marginal rate of transformation (MRT) (i.e., for a relatively rich household), the 
topping-up option might have positive value and, hence, might affect the political support for the status quo. However, poor households in our setup are typically faced with the opposite situation where their MRS is less than their MRT and the topping-up option does not have positive value. The number of households who are better off with the topping-up option is clearly important for the support for vouchers.

When we switch from the status quo to the uniform vouchers, the size of the pie (i.e., the total public spending on education) as well as the distribution of the pie changes. We first isolate the effect of the distribution of the pie. We compare the two regimes by fixing the size of the pie to be the same as that in the status quo (by fixing the tax rate at the status quo level). With the same tax rate, the rich households who chose private education in the status quo would be better off since part of the cost of private education is offset by the voucher. The poor households receive a smaller voucher than the educational expenditure in the status quo since the tax revenues are distributed among all households in the uniform voucher regime instead of among just those who chose public education in the status quo. Despite the lower voucher amount, some households could take advantage of the topping-up option in the uniform voucher regime if the overall resources available to them are sufficiently large and if their consumption-voucher bundle is such that their MRS is greater than their MRT. Quantitatively, however, it turns out that the topping-up option does not make the poorer households better off relative to the status quo, either because the overall resources are not sufficiently large or because their MRS is less than their MRT. Consequently, a majority of households prefer the status quo to uniform vouchers.

To account for the change in the size of the pie due to the change in the education finance regime, we calculate the majority voting equilibrium tax rate in the voucher regime. The uniform voucher regime yields a higher equilibrium tax rate relative to the status quo. When we conduct an election between the status quo and uniform vouchers, we find that the uniform voucher regime is unable to garner a majority of the votes. We also show that the electoral defeat of vouchers is robust to empirically plausible specifications of partial voter 
turnout and higher efficiency of private schools. Crucial to the electoral defeat result is the opting-out feature in the status quo. If the status quo were a pure public education regime, then the voucher regime would emerge as electoral winner in our model.

Much of the political economy literature on education vouchers focuses on selective vouchers given to those who choose private school (i.e., the rich). Examples of these types of analyses include Rangazas (1995) and Hoyt and Lee (1998). ${ }^{1}$ The paper closest to our analysis here is by Chen and West (2000). They study uniform vouchers as well as vouchers targeted at the poor. Unlike Chen and West, we study how the political support for or opposition to vouchers is distributed across income classes. Moreover, we quantify the size of the welfare losses or gains. We also study the political support for vouchers when more high-income households participate in the election relative to low-income households. Epple and Romano (1996b) study a financing system where the government provision may be supplemented by private market purchases, and Fernandez and Rogerson (2003) study a foundation system with local districts topping up a publicly provided base amount. Both systems resemble our uniform voucher regime. While the status quo in our analysis is a mixed education regime, Epple and Romano (1996b) focus on comparisons to pure public and pure private provision while Fernandez and Rogerson (2003) consider several models, including pure public (state) provision. In an election between a status quo of pure public provision and their version of vouchers, the latter emerges as the winner. We show that their result is reversed if the status quo is a mixed regime in which both public and private provisions co-exist and households can opt out. We also demonstrate our result for the cases of partial voter turnout and higher efficiency of private schools.

Our paper is structured as follows. In Section 2, we present two stylized models - one representing the status quo, which has publicly provided education and private education options, and another representing the voucher regime in which an education voucher is given to everyone. In Section 3, we calibrate the status quo model to match features of the U.S.

\footnotetext{
${ }^{1}$ Other work on education vouchers includes Nechyba (1999, 2000), Cohen-Zada and Justman (2003, 2005), Ferreyra (2007), and Bearse, Glomm, and Ravikumar (2000).
} 
data. We then conduct computational experiments to examine the popular support and the distribution of welfare gains for the uniform voucher regime relative to the status quo. Concluding remarks are contained in Section 5. Proofs are relegated to Appendix A and sensitivity analyses are in Appendix B.

\section{Model}

In this section, we briefly review the mixed education model of Epple and Romano (1996a) and Glomm and Ravikumar (1998). ${ }^{2}$ We choose the mixed public-private regime as our status quo since it is a good description of the current K-12 education system in the U.S. and in many other countries. In this discrete-choice regime, households can opt out of public education by sending their children to private schools instead, albeit at their own cost.

The economy is populated by a large number of households. We normalize the size of the population to 1 . Households differ only by income, $y$, which is endowed across households according to the c.d.f. $F$ (p.d.f. $f$ ); the p.d.f. is assumed to be continuously differentiable. We label households by their income and refer to a household with income $y$ as "household $y$." The support of $F$ is $\mathbb{R}_{+}$and mean income, $Y$, exceeds median income, $y_{m}$.

Households derive utility from a numeraire consumption good $c$ and education $e$. The consumption good refers to all goods and services that the household prefers other than education. The preferences of each household are represented by the CRRA utility function:

$$
u(c, e)=\left\{\begin{array}{cl}
\frac{1}{1-\sigma}\left(c^{1-\sigma}+\delta e^{1-\sigma}\right), & \sigma>0, \sigma \neq 1, \quad \delta>0, \\
\ln c+\delta \ln e, & \sigma=1 .
\end{array}\right.
$$

Theoretical results in Subsections 2.1 and 2.2 are valid for more general preferences. However, the quantitative results in Section 3 rely on the CRRA functional form.

\subsection{Mixed Public-Private Education Regime (Status Quo)}

The government uses the tax revenues, $\tau Y$, to provide educational services. All households face a discrete choice: publicly provided education or private education. Households who

\footnotetext{
${ }^{2} \mathrm{~A}$ similar model where public and private alternatives coexist has recently been used by Borck and Wrohlich (2011) to study childcare preferences.
} 
choose public education receive the same educational services, $E=\frac{\tau Y}{N}$, where $N$ is the proportion that chooses public education.

Households who opt out of publicly provided education have to pay the full cost of private education. Expenditure on private education is specific to the household. The market for $e$ is assumed to be perfectly competitive with a large number of producers facing identical technologies exhibiting constant marginal costs. We measure units of $e$ so as to normalize its price to one unit of consumption. Each household allocates the after-tax income to consumption and educational services, that is,

$$
e=(1-\tau) y-c
$$

If household $y$ chooses public education, the allocations and indirect utility are

$$
\begin{aligned}
c & =(1-\tau) y, \quad e=E=\frac{\tau Y}{N} \\
V(\tau, y, N \mid p u b l i c) & =\frac{1}{1-\sigma}\left\{(1-\tau)^{1-\sigma} y^{1-\sigma}+\delta\left(\frac{\tau Y}{N}\right)^{1-\sigma}\right\} .
\end{aligned}
$$

Choosing private education involves maximizing (1) subject to the constraint (2), with solution and indirect utility, respectively, given by

$$
\begin{gathered}
c=\frac{1}{1+\delta^{\frac{1}{\sigma}}}(1-\tau) y, \quad e=\frac{\delta^{\frac{1}{\sigma}}}{1+\delta^{\frac{1}{\sigma}}}(1-\tau) y, \\
V(\tau, y \mid \text { private })=\frac{\left\{1+\delta^{\frac{1}{\sigma}}\right\}^{\sigma}}{1-\sigma}(1-\tau)^{1-\sigma} y^{1-\sigma} .
\end{gathered}
$$

A household chooses public education over private if and only if $V(\tau, y, N \mid$ public $) \geq$ $V(\tau, y \mid$ private $)$. A critical income $\widehat{y}$ exists such that all households with incomes below (above) $\widehat{y}$ choose public education (private education). The critical income $\widehat{y}$ is a continuous function of $\tau$ and $N$. Glomm and Ravikumar (1998) show that there exists a unique $N^{*} \in$ $(0,1)$ that solves the consistency condition $N=F(\widehat{y})$ for all $\tau \in(0,1)$. Denote the fixed point as $N(\tau)$.

An equilibrium for this economy is an allocation across households, $\{c, e\}$, a critical income, $\widehat{y}$, and aggregate outcomes $\{N, E, \tau\}$ that satisfy: (i) given $E$ and $\tau$, the allocations $\{c, e\}$ and school choice are utility maximizing for all households, (ii) enrollment in public 
education is $N=F(\widehat{y})$, (iii) the government's budget is balanced, and (iv) there does not exist another tax rate $\tau^{\prime}$ that beats $\tau$ in majority voting.

The decisive voter $\left(y_{d}^{S Q}\right.$, where the superscript $S Q$ refers to status quo) chooses public education and his most preferred tax rate is the unique solution to

$$
\max u\left((1-\tau) y_{d}^{S Q}, \frac{\tau Y}{N(\tau)}\right) .
$$

For $\sigma \leq 1$, the decisive voter is household $y_{m}$. For $\sigma>1$, the decisive voter is defined by $F\left(y_{h}\right)-F\left(y_{d}^{S Q}\right)=0.5$, where $y_{h}$ is the income of the household that is indifferent between public and private education.

\subsection{Uniform Vouchers}

In a uniform voucher regime, each household receives the voucher amount $v$, so we can write the government budget constraint as $v=\tau Y{ }^{3}$ Each household treats $v$ and $\tau$ as given and chooses the pair $(c, e)$ so as to maximize utility $u(c, e)$ subject to the budget constraint

$$
c+e \leq(1-\tau) y+\tau Y, \quad c \leq(1-\tau) y
$$

If the upper bound on consumption is binding for household $y$, then its choices are

$$
c=(1-\tau) y, \quad e=\tau Y
$$

If the upper bound is not binding, then household $y$ supplements the voucher and its optimal choices are

$$
c=\frac{1}{1+\delta^{\frac{1}{\sigma}}}\{(1-\tau) y+\tau Y\}, \quad e=\frac{\delta^{\frac{1}{\sigma}}}{1+\delta^{\frac{1}{\sigma}}}\{(1-\tau) y+\tau Y\} .
$$

For income distributions with support $\mathbb{R}_{+}$, there exist low-income households who do not supplement their voucher and high-income households who do supplement their voucher.

An equilibrium for the uniform vouchers economy is an allocation $(c, e)$ across households and a public policy $(v, \tau)$ satisfying: (i) Each household's choice of $(c, e)$ is individually rational given public policy $(v, \tau)$; (ii) $\tau$ is a majority winner; and (iii) the government runs

\footnotetext{
${ }^{3}$ As noted in the introduction, vouchers are merely instruments used by the government to finance education; the government does not directly provide education. In our model of vouchers, a "school" is similar to a "firm" in the neoclassical model. Schools simply convert resources to educational services, so we do not refer to "public" or "private" schools.
} 
a balanced budget - that is, $v=\tau Y$.

Denote the decisive voter by $y_{d}^{U}$, where the superscript $U$ refers to Uniform vouchers. The proposition below describes the majority voting equilibrium.

Proposition 1 (i) Households' preferences over $\tau$ are single-peaked and there exists a majority voting equilibrium tax rate. (ii) If $\sigma \leq 1$, then the decisive voter is household $y_{m}$ and the majority preferred tax rate is given by

$$
\frac{\delta(\tau Y)^{-\sigma}}{\left((1-\tau) y_{m}\right)^{-\sigma}}=\frac{y_{m}}{Y},
$$

and if $\sigma>1$, then the decisive voter, $y_{d}^{U}$, is implicitly determined by $1-F(Y)+F\left(y_{d}^{U}\right)=0.5$, and the majority preferred tax rate is given by

$$
\frac{\delta(\tau Y)^{-\sigma}}{\left((1-\tau) y_{d}^{U}\right)^{-\sigma}}=\frac{y_{d}^{U}}{Y} .
$$

The median voter theorem applies for all values of $\sigma$. When $\sigma \leq 1$, the most preferred tax rate is monotonic in income and the decisive voter is the median income household. However, when $\sigma>1$, the most preferred tax rate is not monotonic in income and the decisive voter is defined by $1-F(Y)+F\left(y_{d}^{U}\right)=0.5$. The case where $\sigma>1$ corresponds to an ends against the middle voting equilibrium as in Epple and Romano (1996b). The above proposition is related to the results in Epple and Romano (1996b) for a system where government provision may be supplemented by private market purchases and to the results on the foundation system in Fernandez and Rogerson (2003).

\section{$3 \quad$ Are Vouchers Electable?}

In this section, we examine quantitatively whether uniform vouchers can garner a majority of the votes compared with the status quo mixed public-private education regime. ${ }^{4}$ As noted in the introduction, the voucher regime offers a "topping-up" option, whereas the status quo does not. We compare the status quo against uniform vouchers when the tax rate is fixed

\footnotetext{
${ }^{4}$ Our analysis is motivated by the experiences with the voucher proposals in California in 1993 and 2000, which were both defeated at the ballot box.
} 
at the status quo level. What sets our analysis apart from Epple and Romano (1996b) and Fernandez and Rogerson (2003) is that both of these papers make the welfare and political economy comparison to either a purely public provision regime or a purely private provision regime. We compare vouchers to a mixed regime where public and private provisions co-exist.

Given the same tax rate, each household's constraint on consumption is identical in both regimes: $c \leq(1-\tau) y$. For the households who chose private education in the status quo, the voucher regime offers $\tau Y$ in education spending while the status quo offers nothing. Thus, such households (fraction $1-N$ of the population) are strictly better off in the voucher regime. For the households who chose public education $(N)$ in the status quo, the voucher amount is less than the educational expenditure in the status quo. This is because the tax revenues are distributed among all households in the uniform voucher regime, whereas in the status quo only those who chose public education receive the tax revenues. One might conclude then that all of $N$ households would oppose the voucher regime in an election between the status quo and the vouchers. That would be correct, however, for only some of the $N$ households. For households at a consumption-voucher bundle where the MRS is less than the MRT, the topping-up option has no value. (This is the case for relatively poor households.) These households are constrained in their education spending and cannot move in the direction of fewer educational services and more consumption (see Figure 1(a)).

Even though the voucher amount is lower, some of the $N$ households might be better off if their consumption-voucher bundle is such that their MRS is greater than their MRT (see Figure 1(b)). Such households (e.g., the relatively rich) could use the topping-up option to increase educational services by reducing their consumption and thereby make themselves better off, provided the overall resources available to them are sufficiently large.

The electability of vouchers then depends on how many households chose private education in the status quo and how many among those that chose public education can use the topping-up option to make themselves better off. This is a quantitative question.

In order to answer the question, we calibrate the status quo model to match certain 
(a) Trade-offs for a poor household

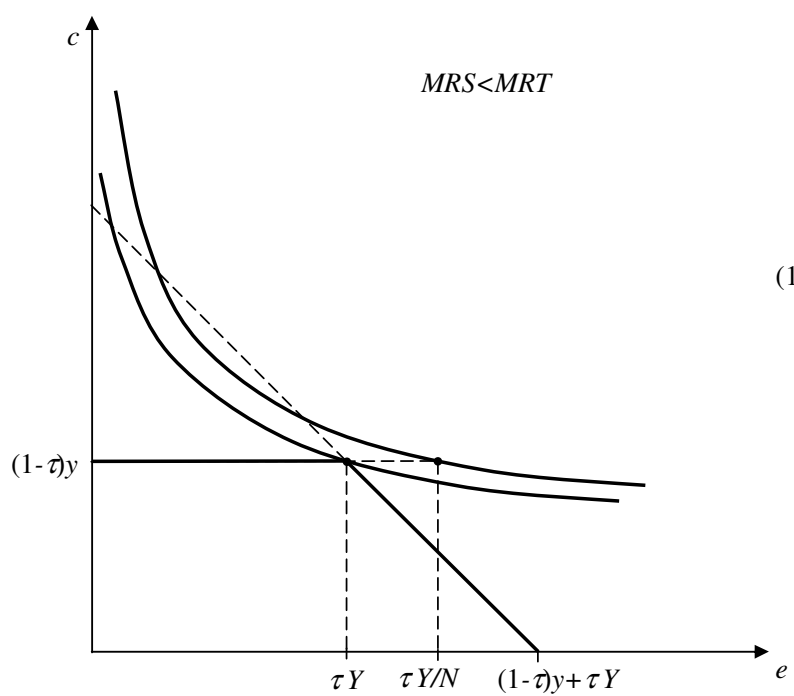

(b) Trade-offs for a wealthy public school household

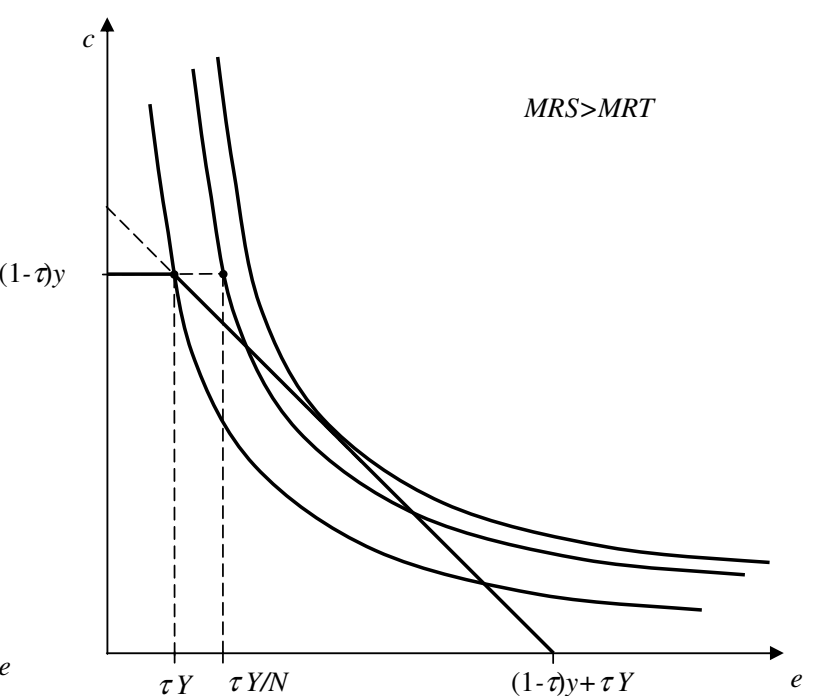

Figure 1: Trade-offs for (a) a poor household and (b) a wealthy household who chooses public education in the status quo.

features of the U.S. data and then examine who gains and who loses when we switch to a uniform voucher regime. Our status quo model is parsimonious: Other than the parameters of $F(y)$ that we take directly from the data on household income distribution, we have only two preference parameters in (1), $\delta$ and $\sigma$, to calibrate. To implement our quantitative analysis, we assume a lognormal $\left(m, s^{2}\right)$ income distribution, following Epple and Romano (1996a). We choose $m=3.36$ and $s=0.68$ to match the mean and median incomes in the U.S. household income distribution in 1989, measured in thousands of dollars. We choose $\sigma$ $=1.54$ and $\delta=0.02$ to match public funding per public school pupil of $\$ 4,222$ in the 1989 U.S. data (assuming 0.5 pupils per household) and an implied price elasticity of demand for public education equal to -0.67 . The values of the calibrated parameters are presented in Table 1.

These values imply an equilibrium tax rate of 5.18 percent. They also imply that the bottom 88 percent of households choose public education and the top 12 percent opt out, which is consistent with the school enrollment data. 


\begin{tabular}{|c|c|c|c|c|c|}
\hline Parameters & \multicolumn{5}{|c|}{ Variables Matched } \\
\hline \multirow{3}{*}{$\begin{array}{l}m=3.36 \\
s=0.68\end{array}$} & & Model & \multicolumn{3}{|c|}{ U.S. Data } \\
\hline & Median Income & $\$ 28,789$ & \multicolumn{3}{|c|}{$\$ 28,906$} \\
\hline & Mean Income & $\$ 36,257$ & \multicolumn{3}{|c|}{$\$ 36,250$} \\
\hline \multirow{3}{*}{$\begin{array}{l}\sigma=1.54 \\
\delta=0.02\end{array}$} & & & & Model & U.S. Data \\
\hline & \multicolumn{3}{|c|}{$\begin{array}{c}\text { Public Education Expenditure } \\
\text { per Public Household }\end{array}$} & $\$ 2,126$ & $\$ 2,111$ \\
\hline & \multicolumn{3}{|c|}{$\begin{array}{l}\text { Implied Price Elasticity of } \\
\text { Demand for Public Education }\end{array}$} & -0.67 & -0.67 \\
\hline
\end{tabular}

Table 1: Calibrated values for model parameters

\subsection{Results}

As noted earlier, in the voucher regime the tax revenues are distributed among all households, whereas in the status quo the tax revenues are distributed only among those who choose public education. Thus, in our model, the bottom 88 percent receive less in vouchers than the educational spending they received in the status quo and the top 12 percent (who had opted out of public education) receive more than they did under the status quo. Clearly, the top 12 percent would favor vouchers. As we argued earlier, some of the bottom 88 percent would also be in favor of vouchers. For households above the 68th percentile, the consumption-voucher bundle is such that their MRS is greater than their MRT. The resources of these households are sufficiently large to top up the vouchers and move to a better consumption-education bundle as in Figure 1(b). Hence, the households between the 68th and 88th percentile favor the voucher regime relative to the status quo.

Households below the 41st percentile in our model are constrained as illustrated in Figure 1(a). Their consumption is the same as that in the status quo but their educational services are lower in the voucher regime. These households would favor the status quo.

Households between the 41st and 68th percentiles are not constrained and find the topping-up option valuable, but their overall resources are not large enough to achieve an allocation superior to what they had in the status quo. Thus, the bottom 68 percent prefer the status quo to the uniform vouchers.

Figure 2(a) illustrates educational services across households in both regimes. In the 
(a) Education Expenditure

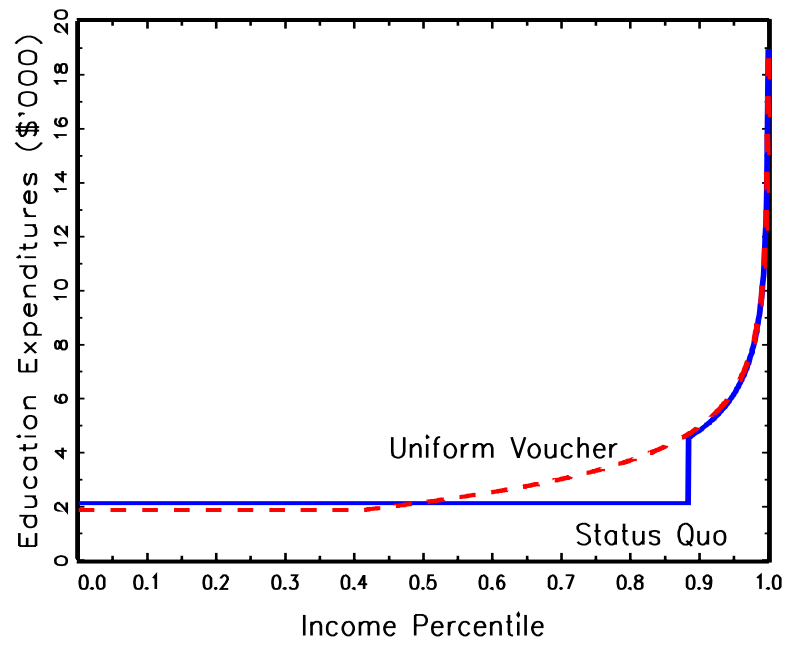

(b) Welfare Gains

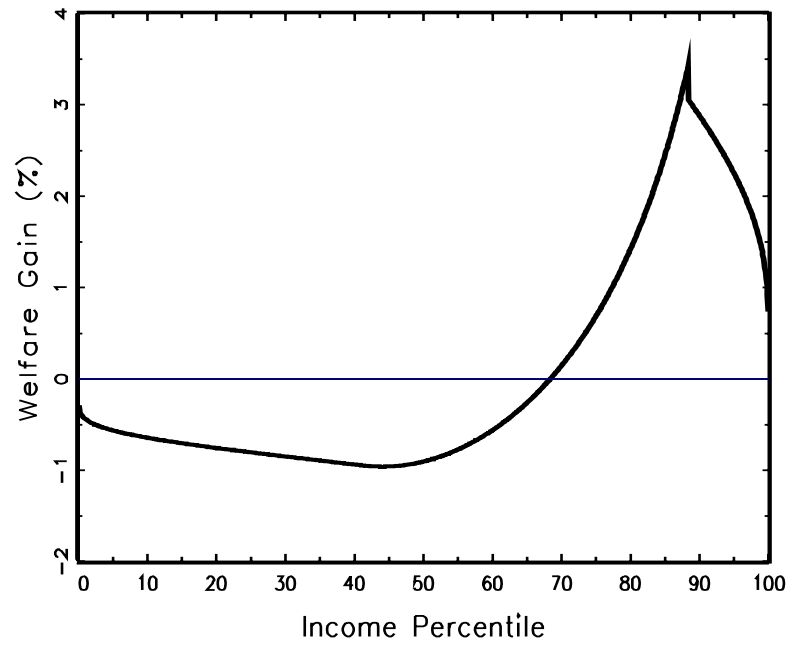

Figure 2: (a) Educational services under status quo and uniform voucher regimes, and (b) Welfare gains from switching to uniform vouchers with the status quo tax rate.

voucher regime, poor households with incomes below the 40th percentile receive less education than in the mixed regime because the public dollars are spread out over more children than in the mixed regime. Households above the 41st percentile top up the voucher by reducing their consumption. Note that all households above the 49th percentile consume more education services even relative to the status quo. This includes the top 12 percent who consume more education services because of the income effect of the voucher, though this is a small effect as can be seen in Figure 2(a). However, for households between the 41st and 68th percentiles, the optimal $(c, e)$ bundle in the voucher regime does not yield a higher utility relative to the allocation in the status quo.

Below we provide a welfare metric for the gains or losses to each household as we switch from the status quo to the uniform voucher regime. Our metric $\omega$ is invariant to monotonic transformations of the utility function and it solves

$$
V^{S Q}(y(1+\omega))=V^{U}(y)
$$

where $V^{S Q}(y(1+\omega))$ denotes the utility that a household with income $y(1+\omega)$ receives in the status quo regime and $V^{U}(y)$ indicates the utility that household $y$ receives in the 
uniform voucher regime. The equivalent variation $\omega$ represents the income transfer, measured in percent, that would make household $y$ indifferent between the status quo and the uniform voucher regimes. When $\omega$ is positive, household $y$ would be worse off in the status quo without the compensating variation. The uniform voucher regime then represents a welfare improvement from the household's perspective and $\omega$ is the magnitude of the welfare gain.

Figure 2(b) illustrates the distribution of welfare gains across households. The welfare losses to the households below the 68th percentile are less than roughly 1 percent of their income, while some of the households above the 68th percentile gain as much as 3 percent. The largest welfare gains from introducing vouchers accrue to those households who in the status quo regime are just below the critical income level that separates public from private school choosers. For these households, the "one size fits all" aspect of public education in the status quo generates the largest deviations from the privately optimal education expenditures and the vouchers allow them to undo these losses. For the top 12 percent of the income distribution (the private school users in the status quo), the voucher must enhance their welfare as the tax rate is fixed. However, as income increases, the welfare gain decreases since the voucher is uniform.

\subsubsection{Role of opting-out}

Critical to our conclusion on the electability of vouchers is the opting-out feature in the status quo. Suppose, instead, that the U.S. economy were modeled as a universal public education regime - that is, the tax revenues are distributed equally across the whole population as public education and no one opt can out. Then, $N=1$ and $e=E=\tau Y$ for all households. (By construction, $N=1$ is inconsistent with the observed enrollment in public and private schools.) Given the same tax rate, the voucher amount for each household would be identical to the education spending under universal education. However, household $y$ in the universal public education regime is stuck with the bundle $c=(1-\tau) y$ and $e=\tau Y$, whereas in the voucher regime it has the option of increasing $e$ and decreasing $c$ subject to overall resources of $(1-\tau) y+\tau Y$. Households for whom the option has positive value would strictly 
prefer the voucher regime. Clearly, no household is worse off in the voucher regime and some households are better off. Hence, in an election between the universal public education regime and uniform vouchers, the voucher regime would win.

The above argument does not hinge on the exact value of $\delta$ and $\sigma$ or on the tax rate. In fact, if we were to recalibrate the model as if the U.S. economy were a universal public education regime, the equilibrium tax would be higher. In order to match the price elasticity and public spending per household, we set $\delta=0.016$ and $\sigma=1.54$. Household $y$ 's most preferred tax rate solves

$$
\max _{\tau \in[0,1]} \frac{1}{1-\sigma}\left\{[(1-\tau) y]^{1-\sigma}+\delta(\tau Y)^{1-\sigma}\right\} .
$$

These preferences are single-peaked in $\tau$ for all $\sigma$ and the majority voting equilibrium existence theorem in Black (1958) applies. Furthermore, the most preferred tax rate is monotonic in income, so the median income household is the decisive voter for all $\sigma$. The equilibrium tax rate in the universal public education regime is 5.82 percent. Again, if we fix the tax rate at 5.82 percent and distribute the revenues equally across households in the form of vouchers, then the voucher regime would be preferred to the universal public education regime.

To summarize, even though the bottom 88 percent receive less in the uniform voucher regime relative to the status quo mixed education regime, only the bottom 68 percent oppose the vouchers. Despite the topping-up option available with vouchers, a majority of households prefer the status quo. If the status quo were not a mixed education regime but a universal public education regime instead, then the voucher regime would win at the polls.

Two natural questions arise at this stage. First, since the top 32 percent of the income distribution prefers the voucher regime relative to the status quo, vouchers might be electable if the votes of high-income households carried a greater "weight" relative to others. That is, in contrast to the case where all households vote in the election, suppose that more highincome households participate in the election relative to low-income households, as in the data. In Subsection 3.2, we assign voting probabilities to the households, recalibrate the model parameters, and examine whether the voucher regime defeats the status quo. Second, 
since public schools are as efficient as private schools in our status quo regime, there are no efficiency gains to eliminating public schools and financing education through vouchers. However, if private schools are more efficient, then there could be gains (and more political support) to financing education through vouchers instead of providing education through public schools. To assess any potential gains, we recalibrate the model in Subsection 3.3 with the assumption that private schools are more efficient than public schools. We then examine whether a switch to a uniform voucher regime is preferred by a majority of households.

\subsection{Incomplete Voter Participation}

We use data from the 1990 Statistical Abstract of the United States to assign voting probabilities. Table 2 displays voter participation by income quintile. Within quintiles, we assume that the probability of voting is constant.

\begin{tabular}{|c|c|c|c|c|c|}
\hline Income Quintile & 1 & 2 & 3 & 4 & 5 \\
\hline Proportion Voting & 0.40 & 0.48 & 0.56 & 0.64 & 0.72 \\
\hline
\end{tabular}

Table 2: Voter turnout by income quintile

We maintain the same income distribution parameters as in Table 1 . We recalibrate $\sigma$ and $\delta$ to match the observed price elasticity for public education spending. ${ }^{5}$ With $\sigma=1.5375$ and $\delta=0.0192$ and incomplete voter participation, the equilibrium tax rate is 5.2 percent, compared with 5.18 percent in the calibration under complete voter turnout. The implied education spending per household choosing public education is $\$ 2,110$ and the price elasticity is -0.67 (recall that in the data the corresponding numbers are $\$ 2,111$ and -0.67 ). For these parameters, the enrollment in public education is 89 percent, so only 11 percent of the households opt out.

We then fix the tax rate at 5.2 percent and distribute the tax revenues as vouchers uniformly across all households. Figure 3(a) illustrates the educational expenditures. The topping-up option is now valuable to households above the 44th percentile, compared with

\footnotetext{
${ }^{5}$ Solving for equilibria in this case is identical to the case in which all households vote, except that the identity of the decisive voter must be determined from the income distribution of the voting population instead of that of the full population.
} 
(a) Education Expenditure

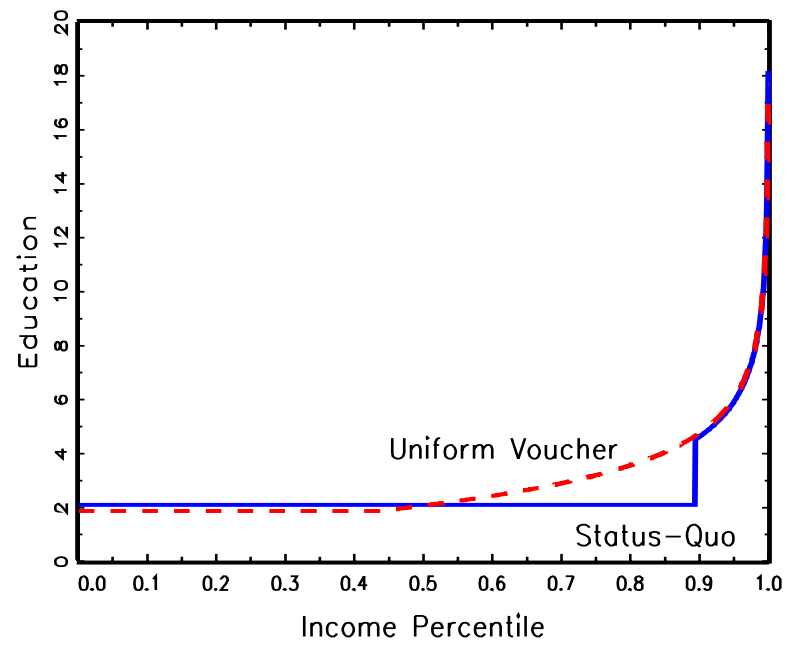

(b) Welfare Gains

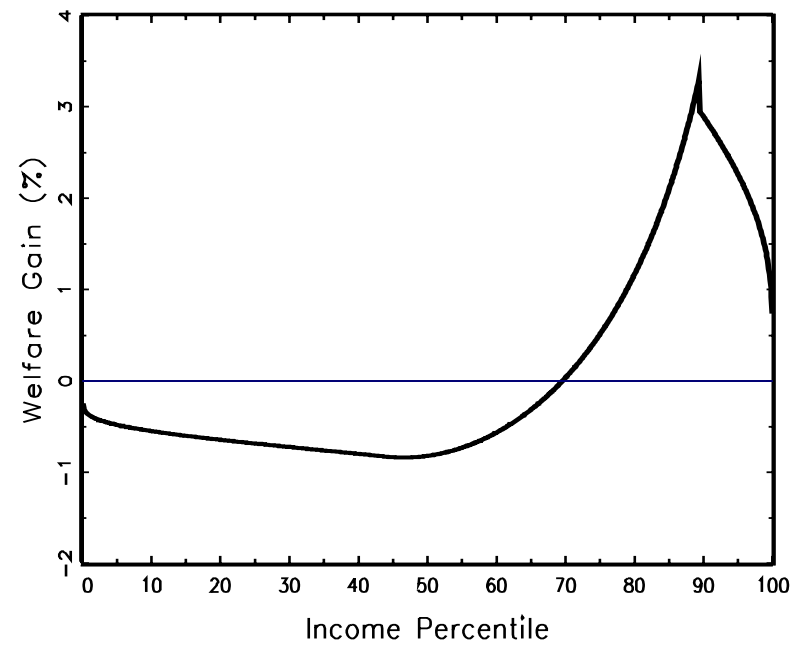

Figure 3: (a) Educational services with the status quo tax rate under partial voter turnout, and (b) Welfare gains from switching to uniform vouchers with the status quo tax rate under partial voter turnout.

the 41st percentile under complete voter turnout. The educational services of households above the 51st percentile exceed that in the status quo. Households below the 44th percentile are constrained and their educational services are less than that in the status quo.

Figure 3(b) illustrates the welfare gains/losses across households. Even though the topping-up option is valuable to households above the 44th percentile, households between the 44th and 69th percentiles do not have enough resources to achieve an allocation superior to what they had in the status quo. In an election between the status quo and the uniform voucher regime, with incomplete voter participation, the former is preferred by more than 62 percent of voting households. Incomplete voter participation increases voter support for vouchers by only 6 percent, not enough to tilt the balance of support above 50 percent.

Thus, despite the fact that higher-income households participate in the election disproportionately more than lower-income households, vouchers are defeated in the polls. 


\subsection{Higher Efficiency of Private Schools}

Voucher proposals might receive greater support if private schools were more efficient than public schools at delivering education services; see, for example, Hoxby (2000) and Epple and Romano (2008). In this subsection, we change the educational services technology and assume that a unit of tax revenue can be converted into one unit of public educational services but can be converted into more than one unit of private educational services. This involves introducing a price for private school education of $p<1$, so the budget for households contemplating private education will change from (2) to

$$
c+p e=(1-\tau) y
$$

The allocations for households choosing public education are unchanged and given by equation (3), while the optimal allocations and indirect utility of households choosing the private alternative are now given by

$$
\begin{gathered}
c=\frac{p^{\frac{1}{\sigma}}}{p^{\frac{1}{\sigma}}+p \delta^{\frac{1}{\sigma}}}(1-\tau) y, \quad e=\frac{\delta^{\frac{1}{\sigma}}}{p^{\frac{1}{\sigma}}+p \delta^{\frac{1}{\sigma}}}(1-\tau) y \\
V(\tau, y \mid \text { private })=\frac{\left\{p^{\frac{1}{\sigma}}+p \delta^{\frac{1}{\sigma}}\right\}^{\sigma}}{p(1-\sigma)}(1-\tau)^{1-\sigma} y^{1-\sigma} .
\end{gathered}
$$

The lower price on private education implies that the marginal household who was indifferent between the public and private schools will now choose private education, so the enrollment in public schools will be lower, all else constant. Of course, the equilibrium tax rate will change as a result of the changes in the households' school choices.

The uniform voucher proposal is similar to that outlined in Section 2.2, with a budget constraint reflecting the assumed efficiency gains

$$
c+p e=(1-\tau) y+\tau Y, \quad c \leq(1-\tau) y .
$$

In the voucher regime, each dollar translates into higher educational services for both constrained and unconstrained households. For instance, the allocations for the constrained households are $c=(1-\tau) y$ and $e=\frac{\tau Y}{p}$, and the allocations for the unconstrained house- 
holds are

$$
c=\frac{p^{\frac{1}{\sigma}}}{p^{\frac{1}{\sigma}}+p \delta^{\frac{1}{\sigma}}}\{(1-\tau) y+\tau Y\} \quad \text { and } \quad e=\frac{\delta^{\frac{1}{\sigma}}}{p^{\frac{1}{\sigma}}+p \delta^{\frac{1}{\sigma}}}\{(1-\tau) y+\tau Y\} .
$$

In order to study the effects of these potential efficiency gains we need to recalibrate the model. Based on the evidence in Hoxby (2000) on relative efficiencies of public and private schools in the United States, we set $p=0.98$ (the same value is also used by Epple and Romano, 2008). We retain the same income distribution parameters as in our earlier calibration ( $m=3.36$ and $s=0.68$, see Table 1$)$, but we recalibrate $\sigma$ and $\delta$ to deliver the price elasticity of demand and public education expenditures per household in public schools. The resulting parameters are $\sigma=1.5395$ and $\delta=0.0202$. With these parameter values, the equilibrium tax rate is 5.12 percent, the public education expenditure per household is $\$ 2,110$, and the public education enrollment is 88 percent.

Fixing the tax rate at 5.12 percent in the voucher regime does not qualitatively change the results. As might be expected, the introduction of private school efficiency provides additional support for vouchers; 33.3 percent support the voucher in contrast to 32 percent in the benchmark model in which the private and public schools were equally efficient. In terms of welfare gains, the bottom 67 percent of households are worse off with vouchers when private schools are more efficient. (See Figures 7 and 8 in Bearse et al. (2011) for more details.) Thus, while empirically plausible efficiency differentials provide a small boost for vouchers, they are insufficient to overturn the electoral defeat of vouchers. Clearly, as the efficiency differential increases, the support for vouchers will increase as well.

\section{Political Support for Vouchers with Endogenous Tax}

In the previous section, we held the size of the education spending pie fixed, but distributed the pie differently when we switched from the status quo to the uniform vouchers. The critique by Lucas (1976) would suggest that we should endogenize the tax rate in the voucher regime and then compare with the status quo. Put differently, the decisive household in our model might favor the voucher regime if it accounted for the change in the size of the pie 
due to the change in the education regime. We examine this possibility below.

The parameters of the status quo are the same as in Table 1, so the majority voting equilibrium tax rate under the status quo remains 5.18 percent. Using part (ii) of Proposition 1 to determine the majority voting equilibrium in the uniform voucher regime, we obtain a tax rate of 5.34 percent. Thus, the size of the pie in the uniform voucher regime is larger. The voting equilibria in both the status quo and the uniform voucher regimes are the ends against the middle equilibria. In the voucher regime, the tax revenue is distributed over more households than in the status quo and, as a consequence, all those voting for nonzero taxes vote for a higher tax in the voucher regime. The result is a higher equilibrium tax rate in the voucher regime.

Despite the larger pie, each household receives a voucher less than the public education spending in the status quo $(\$ 1,936$ versus $\$ 2,126)$, since the (larger) pie is now distributed among all households instead of just the 88 percent in status quo. Households who are constrained in the voucher regime (as in Figure 1(a)) are clearly worse off since their consumption is less relative to the status quo (due to a higher tax rate) and their educational services are less (due to a lower voucher amount). Figure 4(a) illustrates the educational services across households. The constrained group constitutes all households below the 43rd income percentile that choose not to supplement the voucher.

For households between the 43rd and 68th percentiles, their optimal $(c, e)$ bundle is not superior to that in the status quo even though they top up the voucher amount by reducing consumption. As a result, at least 68 percent of households prefer the status quo to the uniform voucher regime. ${ }^{6}$ Figure $4(\mathrm{~b})$ depicts the gains and losses to various households. Note that while only the top 12 percent choose private education in the status quo, almost the entire top 32 percent prefer the higher tax and the uniform voucher since they can

\footnotetext{
${ }^{6}$ The very rich households (above the 99 th percentile) are strictly better off in the status quo. The tax rate in the status quo is lower, but the uniform voucher regime offers $\$ 1,936$, whereas the status quo offers zero. However, the higher after-tax income in the status quo more than offsets the voucher amount for the very rich households.
} 
(a) Education Expenditure

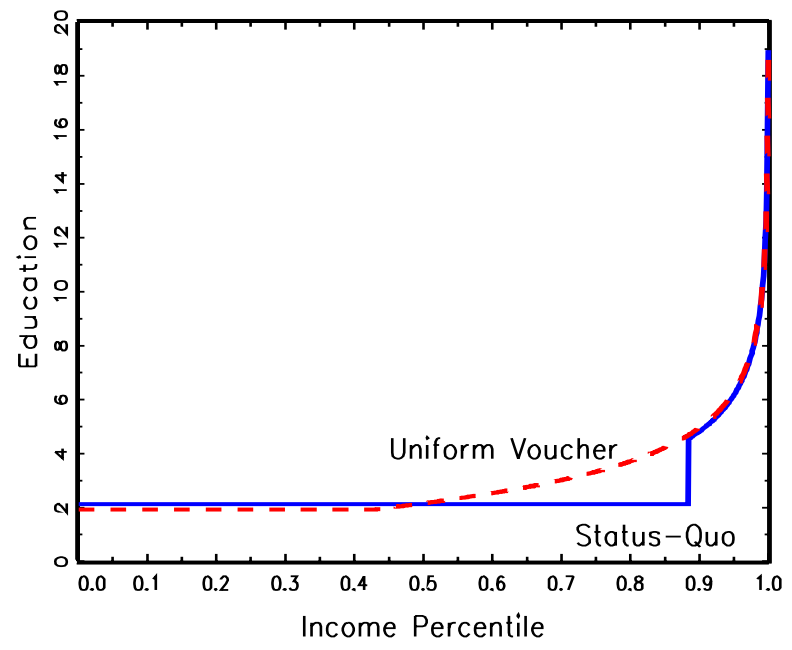

(b) Welfare Gains

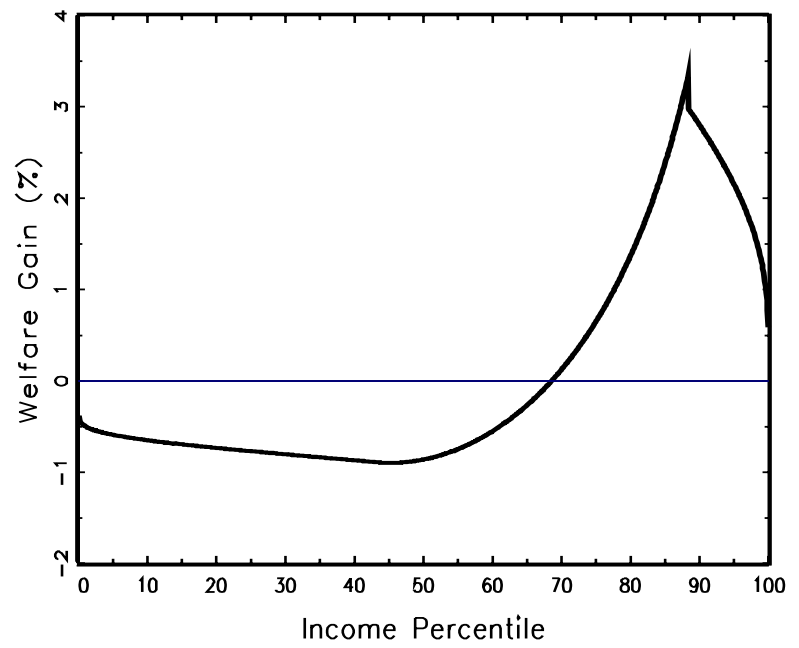

Figure 4: (a) Educational services with endogenous taxes under status quo and uniform voucher regimes, and (b) Welfare gains from switching to uniform vouchers with endogenous tax rate.

supplement the voucher and attain higher utility. ${ }^{7}$

As in the exogenous tax rate case, the opting-out feature is crucial for the electoral defeat of uniform vouchers in the endogenous tax rate case. If, instead of allowing the private school option, public education were universally required, then the calibrated parameters in Subsection 3.1.1 would imply that the uniform voucher regime has an equilibrium tax rate of 4.52 percent and a voucher amount of $\$ 1,639$ per household. In a pairwise election between the universal public education regime and the voucher regime, the voucher regime is supported by the bottom 29 percent and the top 37.5 percent of the income distribution. Thus, uniform vouchers will not suffer an electoral defeat against a universal public education regime. $^{8}$

Partial voter turnout, as in Table 2, does not alter the result that the voucher regime is defeated at the polls. With partial voter turnout, the tax rate in the status quo is 5.2

\footnotetext{
${ }^{7}$ The finding that opposition to vouchers comes from the lowest income households is consistent with empirical evidence in Catterall and Chapleau (2003), who study a voucher similar to the one modeled here - the California voucher proposal from the year 2000, Proposition 38.

${ }^{8}$ Epple and Romano (1996b) and Fernandez and Rogerson (2003) find a similar result for models that resemble our uniform voucher regime.
} 
percent (see Subsection 3.2) and the tax rate in the uniform voucher regime is 4.74 percent. The voucher amount is clearly less than the spending per public education household in the status quo $(\$ 1,719$ versus $\$ 2,110)$. In an election between the status quo and uniform vouchers, the status quo again emerges as the winner, with the poorest 62 percent of voting households supporting it.

Endogenizing the voucher tax rate under the assumption of higher private school efficiency does not qualitatively change the result either. Using the setup from Subsection 3.3, the equilibrium tax rate in the uniform voucher regime is 5.28 percent with a voucher value of $\$ 1,914$. Political support for the voucher regime is virtually unchanged with only the top 33 percent of the income distribution supporting it. Overall, endogenizing the tax rate does not qualitatively change the support for the uniform voucher regime.

\section{Concluding Remarks}

We studied an environment in which tax revenues are distributed uniformly across households in the form of education vouchers. We calibrated the status quo mix of public and private education to the U.S. data. When we distribute the status quo tax revenues as uniform vouchers, the vouchers do not have a majority support to replace the status quo. Our result is robust to a partial turnout in elections: Even if richer households participate in elections at a higher rate relative to poorer households, vouchers suffer an electoral defeat. Our result is also robust to an empirically plausible efficiency differential between public and private schools. Critical to the electoral defeat result is the opting-out feature in the status quo: Rich households can opt out of public education and send their children to private schools.

Opposition to uniform vouchers in our model comes from most of the households who choose public education in the status quo (opposition comprises the bottom 68 percent in our benchmark calibration). This opposition could be overcome by distributing the status quo tax revenues as vouchers to fewer households instead of distributing to all households. For instance, in our benchmark calibration, the status quo tax revenues are available to 88 
percent of households (the ones who chose public education), so distributing these revenues as vouchers to only 50 percent of these households would clearly generate majority support for vouchers. A more general approach to secure electoral victory for vouchers might be to abandon uniform vouchers and use means-tested vouchers instead. This is the approach we follow in related research.

In our model, households are differentiated only by income and, hence, political support for the status quo versus education vouchers is purely driven by income heterogeneity. Merzyn and Ursprung (2005) study support for education vouchers and privatization in Switzerland. They find a positive relationship between income and voting for a more privatized education system. These findings lend support for our focus on the income heterogeneity to determine political outcomes.

We have not explicitly included housing in our model. First, to the extent that public education is financed by local property taxes, a switch to a voucher regime could affect property values and, hence, the tax revenues available to fund education vouchers. However, the reliance of public education funding on local tax revenues has been declining in the United States. For instance, in 2006-07, in 40 of the 50 states, nonlocal sources financed more than 50 percent of the expenditures on K-12 public education. When measured in terms of student enrollment, 82 percent of the students enrolled in public schools were in states where the nonlocal financing is more than 50 percent (see Figure 11 in Bearse et al. (2011)). Second, the voucher regime's effect on property values could affect the political support for the regime; see, for example, Brunner and Sonstelie (2003). Presumably the change in housing wealth affects the private consumption of housing services and other goods. Our model captures the trade off between a publicly provided good and all other private goods and services, so the effect of a switch to the voucher regime on private consumption of housing services has been accounted for in the model. On the empirical front, Cooper (2009) shows that for most households, changes in housing wealth have negligible effects on consumption. 


\section{Appendix A Proofs}

Proof of Proposition 1. (i) All households with $y>Y$ prefer a tax rate of $\tau=0$ since their tax payments, $\tau y$, exceed the voucher amount. Furthermore, the indirect utility for these households is declining in $\tau$. To establish the single-peakedness for households with $y \leq Y$, define two functions $-\underline{V}$ and $\bar{V}$ :

$$
\underline{V}(y ; \tau) \equiv u((1-\tau) y, \tau Y) ; \quad \bar{V}(y ; \tau) \equiv u(\bar{c}((1-\tau) y+\tau Y), \bar{e}((1-\tau) y+\tau Y)),
$$

where the functions $\bar{c}$ and $\bar{e}$ describe interior solutions given resources $(1-\tau) y+\tau Y$ and no additional constraints. Clearly, $\underline{V} \leq \bar{V}$ since the resource constraint is the same, but $\underline{V}$ has an additional constraint on educational expenditure. Define $\bar{\tau}(y)$ such that $\underline{V}(y ; \bar{\tau})=\overline{\bar{V}}(y ; \bar{\tau})$, that is, at $\bar{\tau}$ household $y$ 's interior choice of educational expenditure is exactly the same as the voucher amount (or, the voucher constraint is just barely binding). It is easy to see that there is a unique $\bar{\tau}(y)$ (set $(1-\tau) y=\bar{c}((1-\tau) y+\tau Y)$ and solve for $\tau)$. Clearly, for a tax rate higher than $\bar{\tau}$, household $y$ would be constrained. We can then write the indirect utility of household $y$ as

$$
V(y ; \tau)=\left\{\begin{array}{lll}
\bar{V}(y ; \tau) & \text { if } \quad \tau<\bar{\tau}(y) \\
\underline{V}(y ; \tau) & \text { if } \quad \tau \geq \bar{\tau}(y)
\end{array} .\right.
$$

For household $y<Y, \bar{V}$ is increasing in $\tau$. For this household, it is also easy to see that $\underline{V}$ is strictly concave in $\tau$. Thus, the indirect utility for household $y, V(y ; \tau)$, is (i) the same as $\bar{V}(y ; \tau)$ for $\tau<\bar{\tau}(y)$ and, hence, increasing and (ii) the same as $\underline{V}(y ; \tau)$ for $\tau \geq \bar{\tau}(y)$ and, hence, strictly concave. At $\bar{\tau}(y)$, by construction, $\underline{V}=\bar{V}$, so there is no discontinuity in $V(y ; \tau)$ at $\bar{\tau}(y)$.

Now, $\underline{V}$ is single-peaked at $\widehat{\tau}(y)$, where $\widehat{\tau}(y)$ is the unique solution to

$$
y u_{1}((1-\tau) y, \tau Y)=Y u_{2}((1-\tau) y, \tau Y) \text {. }
$$

Furthermore, $\widehat{\tau}(y)>\bar{\tau}(y)$. This is because (i) at $\tau=\bar{\tau}(y), u_{1}((1-\tau) y, \tau Y)=u_{2}((1-\tau) y, \tau Y)$ since household $y$ 's optimal choice (based on $\bar{V}$ ) of consumption is exactly the after-tax income and educational expenditure is exactly the voucher amount and (hence) (ii) $\left.\frac{\partial V}{\partial \tau}\right|_{\tau=\bar{\tau}(y)}=$ $u_{1}((1-\bar{\tau}(y)) y, \bar{\tau}(y) Y)\{Y-y\}>0$ for all $y<Y$.

Thus, $V(y ; \tau)$ is single-peaked for all households. The existence of a majority voting equilibrium follows from Black (1958).

(ii) We have already established that the most preferred tax rate of households with $y>Y$ is zero. Now, suppose that the decisive voter is not constrained. Then, $u_{1}(c, e)=u_{2}(c, e)$ where $c<(1-\tau) y_{d}^{U}$ and $e>\tau Y$. Consider an increase in $\tau$. Then, the decisive voter would be better off with a higher $\tau$, as long as his choice of consumption is not constrained by his after-tax income. Hence, his most preferred tax rate has to be such that $\widehat{c}=\left(1-\widehat{\tau}\left(y_{d}^{U}\right)\right) y_{d}^{U}$ and $\widehat{e}=\widehat{\tau}\left(y_{d}^{U}\right) Y$. The most preferred tax rate solves the problem of $\max u\left((1-\tau) y_{d}^{U}, \tau Y\right)$.

(iii) $\widehat{\tau}(y)$ is decreasing in $y$ for $\sigma<1$, invariant to $y$ for $\sigma=1$ and increasing in $y$ for $\sigma>1$. Hence, for $\sigma \leq 1$, household $y_{m}$ is the decisive voter, whereas for $\sigma>1$ the decisive voter is defined by $1-F(Y)+F\left(y_{d}^{U}\right)=0.5$. 


\section{Appendix B Sensitivity Analysis}

In this section, we examine whether our results in Section 3 are robust to alternative parameterizations about preferences and income distribution. We begin with different values for the preference parameters $\sigma$ and $\delta$ while maintaining the benchmark lognormal $\left(3.36,0.68^{2}\right)$ income distribution. We consider three sets of values for $(\sigma, \delta)$, each roughly matching public education expenditure per household of $\$ 2,111$ and one of three implied price elasticities of demand for education when evaluated at the mixed education regime equilibrium. These values are displayed in Table 3, along with the results of elections between the status quo and uniform vouchers. (The benchmark parameters $\sigma=1.54$ and $\delta=0.02$ are also included in the table for comparison.)

\begin{tabular}{|c|c|c|c|}
\hline$\sigma$ & $\delta$ & Price Elasticity & \% Voting for vouchers \\
\hline 2.200 & 0.006 & -0.500 & 40.3 \\
1.540 & 0.020 & -0.670 & 31.4 \\
0.790 & 0.111 & -1.250 & 25.4 \\
0.650 & 0.155 & -1.500 & 23.6 \\
\hline
\end{tabular}

Table 3: Election results for alternative preference parameters

We now change the parameters of the income distribution while maintaining our benchmark preference parameter values of $\sigma=1.54$ and $\delta=0.02$. Under the lognormal income distribution, mean income is given by $Y=\exp \left(m+s^{2} / 2\right)$. We fix mean income at the benchmark value $Y=\exp \left(3.36+0.68^{2} / 2\right) \simeq 36.278$ and perform mean-preserving spreads of the income distribution using $m=3.36+0.68^{2} / 2-\theta^{2} / 2$ for two different values of $\theta$. The different combinations of $s$ and $m$ in Table 4 imply the same mean income but different median incomes. (As is well known for the lognormal distribution, inequality is increasing in $s$.

\begin{tabular}{|c|c|c|c|c|}
\hline$s$ & $m$ & Median $y$ & Gini & \% Voting for vouchers \\
\hline 0.430 & 3.499 & $\$ 33,072$ & 0.239 & 35.5 \\
0.680 & 3.360 & $\$ 28,789$ & 0.385 & 31.4 \\
0.930 & 3.159 & $\$ 23,540$ & 0.489 & 30.2 \\
\hline
\end{tabular}

Table 4: Election results for alternative income distribution parameters

We see that our principal findings on the electability of vouchers in Section 3 are robust to variations in income inequality. The uniform voucher regime is unable to garner a majority of the votes against the status quo. 


\section{References}

[1] Bearse, P., Cardak, B., Glomm, G. and Ravikumar, B., 2011, "Why do education vouchers fail at the ballot box?" Federal Reserve Bank of St. Louis. working paper 2011-032.

[2] Bearse, P., Glomm, G. and Ravikumar, B., 2000, "On the Political Economy of MeansTested Vouchers," European Economic Review, 44:904-15.

[3] Black, D., 1958, The Theory of Committees and Elections, Cambridge: Cambridge University Press.

[4] Borck, R. and Wrohlich, K., (2011), "Preferences for childcare policies: Theory and evidence", European Journal of Political Economy 27(3), 436-454.

[5] Brunner, E. and Sonstelie, J., 2003, "Homeowners, Property Values, and the Political Economy of the School Voucher," Journal of Urban Economics, 54:239-57.

[6] Carnoy, M., 1997, "Is Privatization Through Education Vouchers Really the Answer? A Comment," World Bank Research Observer, 12:105-16.

[7] Catterall, J. S. and Chapleau, R., 2000, "Voting on Vouchers: A Sociopolitical Analysis of California Proposition 38", Journal of Education Finance, 29:25-47.

[8] Chen, Z. and E. G. West, 2000, "Selective Versus Universal Vouchers: Modeling Median Voter Preferences in Education," American Economic Review 90: 1520-1534.

[9] Cohen-Zada, D. and Justman, M., 2003, "The Political Economy of School Choice: Linking Theory and Evidence," Journal of Urban Economics, 54:277-308.

[10] Cohen-Zada, D. and Justman, M., 2005, "The Religious Factor in Private Education," Journal of Urban Economics, 57:391-418.

[11] Cooper, D., 2009, "Impending U.S. Spending Bust? The Role of Housing Wealth as Borrowing Collateral," Federal Reserve Bank of Boston, Public Policy Discussion Paper No. 09-9. http://ssrn.com/abstract $=1520576$

[12] Epple, D. and Romano, R., 1996a, "Ends Against the Middle: Determining Public Service Provision When There Are Private Alternatives," Journal of Public Economics, 62:297-325.

[13] Epple, D. and Romano, R., 1996b, "Public Provision of Private Goods," Journal of Political Economy, 104:57-84.

[14] Epple, D. and Romano, R., 2008, "Educational Vouchers and Cream Skimming," International Economic Review, 49:1395-1435.

[15] Fernandez, R. and R. Rogerson, 2003, "Equity and Resources: An Analysis of Education Finance Systems", Journal of Political Economy, 111:858-897.

[16] Ferreyra, M., 2007, "Estimating the Effects of Private School Vouchers in Multi-District Economies," American Economic Review, 97:789-817.

[17] Friedman, M., 1962, Capitalism and Freedom, Chicago: University of Chicago Press.

[18] Glomm, G. and Ravikumar, B., 1998, "Opting Out of Publicly Provided Services: A Majority Voting Result," Social Choice and Welfare, 15:187-99. 
[19] Hoxby, C. M., 2000, "Does Competition Among Public Schools Benefit Students and Taxpayers? Evidence from Natural Variation in School Districting," American Economic Review, 90:1209-1238.

[20] Hoyt, W. H. and Lee, K., 1998, "Educational Vouchers, Welfare Effects, and Voting," Journal of Public Economics, 69:211-228.

[21] James, E., 1987, "The Public-Private Division of Responsibility for Education: An International Comparison," Economics of Education Review, 6:1-14.

[22] Lucas, R.E. Jr., 1976, "Econometric Policy Evaluation: A Critique," Carnegie-Rochester Conference Series on Public Policy, 1:19-46.

[23] Merzyn, W. and H. W. Ursprung, 2005, "Voter support for privatizing education: evidence on self-interest and ideology," European Journal of Political Economy, 21: 35-58.

[24] Nechyba, T., 1999, "School Finance Induced Migration and Stratification Patterns: The Case of Private School Vouchers," Journal of Public Economic Theory, 1:5-50.

[25] Nechyba, T., 2000, "Mobility, Targeting, and Private School Vouchers," American Economic Review, 90:130-146.

[26] Rangazas, P., 1995, "Vouchers and Voting: An Initial Estimate Based on the Median Voter Model," Public Choice, 82:261-279.

[27] West, E., 1997, "Education Vouchers in Principle and Practice: A Survey," The World Bank Research Observer, 12:83-103. 